\title{
The balance of intrinsic need satisfaction across contexts as a predictor of depressive symptoms in children and adolescents
}

\author{
A. Ann Emery ${ }^{1} \cdot$ Jessica R. Toste $^{2} \cdot$ Nancy L. Heath ${ }^{1}$
}

Published online: 31 March 2015

(c) Springer Science+Business Media New York 2015

\begin{abstract}
The purpose of the present study was to test the applicability of self-determination theory (Deci and Ryan in J Res Pers 19:109-134. doi:10.1016/00926566(85)90023-6, 1985; Can Psychol 49:182-185. doi:10. 1037/a0012801, 2008) across developmental periods by differentiating children and adolescents on the importance of individual needs (i.e., autonomy, competence, relatedness) and the role of balance across contexts (i.e., home, school, peers) in predicting depressive symptoms. Participants completed the Children's Intrinsic Need Satisfaction Scale (Koestner and Veronneau in The Children's Intrinsic Needs Satisfaction Scale. McGill University, Montreal, 2001) and the Children's Depression Inventory (Kovacs in Children's depression inventory manual. MultiHealth Systems, North Tonawanda, 1992). Results indicated that only the need for competence was significantly related to depressive symptoms in the child sample $(n=149)$ whereas, the satisfaction of autonomy and relatedness were significant predictors in the adolescent sample $(n=153)$. In both samples, need balance across contexts was a significant predictor over and above the level of satisfaction of each individual need. Implications for clinical practice and for theory will be presented.
\end{abstract}

Keywords Basic needs · Depression - Children . Adolescents $\cdot$ Self-determination theory

A. Ann Emery

amber.emery@mail.mcgill.ca

1 Department of Educational and Counselling Psychology, McGill University, Montreal, Canada

2 Department of Special Education, The University of Texas at Austin, Austin, TX, USA

\section{Introduction}

Although often neglected in public health research, the general symptoms related to depression such as sadness, irritability, and anhedonia are present and not uncommon in child and adolescent populations (Birmaher et al. 1996; Rushton et al. 2002; Rutter 1986; Scheidt et al. 2000). While some etiological models of child and adolescent depression have been developed, depressive symptomatology in children and adolescents has often been explained and treated using adult models (e.g., Abela et al. 2007; Gibb and Alloy 2006; Prinstein and Aikins 2004). Considering the social-emotional, cognitive, and biological differences between individuals at diverse developmental stages (Cicchetti 1990; Erikson 1950), it makes sense that in order to be of empirical or clinical utility, theories of depression should be unique to the populations upon which they are based.

\section{Cole's competency-based model of child depression}

One such developmentally specific theory is Cole's (1991) competency-based model of child depression. Cole proposes that children actively seek out, receive, and internalize competency-based evaluations and feedback from others (e.g., parents, teachers, peers). Frequent positive feedback in at least one domain, such as academic performance or physical appearance, promotes the development of complex self-schemata that inhibit the emergence of depression. However, frequent negative feedback across a wide variety of domains inhibits the development of such schemata, which in turn, predisposes the child for depression. Cross-sectional and longitudinal research conducted with elementary school children has lent support to this theoretical model (Burt et al. 2008; Burt and Roisman 
2010; Cole 1991; Cole et al. 1997; Heath and Wiener 1996; Masten et al. 2005; Seroczynski et al. 1997). Although Cole issues a developmental caveat, stressing that his model is specific only to the brief developmental period of middle childhood, some empirical findings support the model's applicability to adolescents and young adults (Kessler 1997; Tram and Cole 2000; Uhrlass et al. 2009).

In contrast to Cole's developmentally specific model, Deci and Ryan's widely applied self-determination theory (SDT; Deci and Ryan 1985, 2008; Ryan and Deci 2000) makes predictions for health and positive adaptation across the lifespan.

\section{Self-determination theory}

Self-determination theory offers a broad theoretical framework for understanding motivation. As an organismic approach, SDT is built on the assumption that people are actively involved in their own development with evolved tendencies towards growth and mastery. These natural tendencies towards personal growth do not occur automatically, instead, this positive development is dependent upon an individual's social context. Basic psychological needs theory (BPNT), a mini theory within the formal selfdetermination theory, outlines three universal innate needs that serve as the avenue through which the social context influences development throughout the lifespan: autonomy, competence, and relatedness. The need for autonomy can be understood as the feeling of volition that accompanies an act; for example feeling that one has a choice in what they do and how and when they do it. The need for competence is understood as individuals' inherent desire to feel effective when interacting with the environment (Ryan and Deci 2000). This need manifests in our exploration and manipulation of our environment, and our desire to take on challenging tasks and build upon our skills (van de Broeck et al. 2010). Relatedness is understood as the need for deep social connections and relationships; our need for relatedness is satisfied when we feel close to others. SDT posits that all three needs are essential. When they are fulfilled via the social context, an individual is in the position to maintain optimal functioning and achieve positive personal growth, however, when any one need is thwarted, an individual's overall well-being and psychological health are at risk (Deci and Ryan 1985, 2008; Ryan and Deci 2000).

There has been much empirical evidence to support the association between satisfaction of intrinsic needs and various indices of psychological well-being, such as momentary happiness (Howell et al. 2011), vitality, positive affect (Adie et al. 2012; Bartholomew et al. 2011; Milyavskaya and Koestner 2011; Reis et al. 2000; Sheldon et al. 1996), self-esteem (Amarose et al. 2009; Heppner et al. 2008; Ilardi et al. 1993), relationship functioning and quality (Patrick et al. 2007), and security of attachment (La Guardia et al. 2000). Furthermore, there is empirical evidence to suggest that when needs are not fulfilled, negative psychological consequences result such as unhappiness, dissatisfaction with life, lack of self-actualization (Meyer et al. 2007), disordered eating, burnout, depression, anxiety, negative affect, and physical symptoms (Baard et al. 2004; Bartholomew et al. 2011; Quested et al. 2011; Thøgersen-Ntoumani et al. 2010).

Intrinsic needs, and the stability of SDT, have been explored across various populations, cultures, and contexts. From dancers, to factory workers, to athletes, to modelsfindings point to the strong predictive ability of need satisfaction (Adie et al. 2012; Ilardi et al. 1993; Meyer et al. 2007; Quested et al. 2011). Although SDT makes wellbeing predictions across the lifespan, intrinsic needs research predicting depressive symptomatology has been relatively sparse in child and adolescent samples. Considering the generalizability of SDT and its clear relationship to psychological adjustment, it seems likely that this theory could be a useful framework to guide research on child and adolescent depression.

\section{Self-determination as a theoretical framework for depression in children and adolescents}

SDT has recently been extended to understand depressive symptoms in child and adolescent populations (Milyavskaya et al. 2009; Veronneau et al. 2005). Veronneau et al. (2005) were the first researchers to use reported levels of autonomy, competence, and relatedness as predictors of well-being among 135 third graders and 196 seventh graders. In Quebec, Canada, where the data was collected, seventh grade corresponds to the first year of high school. When comparing the elementary and high school samples on level of need satisfaction, third graders reported experiencing significantly higher levels of competence and relatedness than their seventh grade counterparts. Consistent with previous literature (Finch et al. 1985; Garrison et al. 1990; Scheidt et al. 2000), the elementary school sample had less depressive symptoms and more positive affect, than the high school sample.

When examining the elementary and high school samples together, competence was found to be the only significant predictor of depressive symptoms. This predictive ability remained consistent, with the same effects being measured in the sample in a six-week follow up. Furthermore, the researchers combined levels of autonomy, competence, and relatedness, in order to assess overall need satisfaction across contexts, finding that satisfaction at home and at school, but not with friends, were significant predictors of depressive symptoms. 
Veronneau and colleagues' study was the first to assess the satisfaction of all three needs in children and adolescents and to apply the level of satisfaction to the prediction of well-being as well as the first to examine overall need satisfaction across important life contexts as predictors of well-being variables. The finding that only the fulfillment of the need for competence was important in predicting depressive symptoms at two separate time points lends support to Cole's (1991) model and reflects Ryan and Deci's (2000) attestation that the saliency of some needs may vary with development. However, by combining data from grade three and grade seven students, developmental differences may have been lost. Considering: (a) the differences the researchers found on level of need satisfaction when comparing the two groups; (b) the specificity in Cole's model to the middle childhood developmental period; and, (c) the increased importance of the peer group in emerging adolescence (Berndt 1979; Erikson 1968), one might expect that the needs of autonomy and relatedness, as well as overall need satisfaction with friends may have been stronger predictors had the data been analyzed in a developmentally comparative way.

\section{Including a balance hypothesis}

Addressing the potential developmental overgeneralization in Veronneau et al. (2005) study, Milyavskaya et al. (2009) revisited need satisfaction across contexts in adolescent samples in three related studies. Furthermore, a balance variable was introduced with the researchers hypothesizing that while the amount of need satisfaction reported should be predictive of well-being, the degree to which need satisfaction across contexts is equal should add to this predictive ability.

Sheldon and Niemiec (2006) were the first to identify a self-determination balance construct, hypothesizing that it is not only the amount of need satisfaction that affects wellbeing, but that balance across individual needs of autonomy, competence, and relatedness has an effect as well. To illustrate this construct, Sheldon and Niemiec give the contrasting need profile examples of an entrepreneur and a stay at home mom. The entrepreneur experiences high levels of autonomy satisfaction (a score of 6 on a scale of 1-7) as he is his own boss. The entrepreneur's business is growing and he is successful, he thus experiences high levels of satisfaction of his need for competence (a score of 6). However, because the entrepreneur's work is so demanding, he is finding that he has less time to spend with his family and thus, his need for relatedness is being thwarted (a score of 3). In contrast, a stay at home mother has temporarily put her career on hold to raise her children. She experiences good satisfaction of her needs for autonomy and relatedness as she plans her own days and enjoys the company of her children (a score on 5 for both autonomy and relatedness). Moreover, she has taken on a small job of $15 \mathrm{~h}$ a week in which she is successful, thus, her need for competence is also satisfied (a score of 5). While the entrepreneur and the stay at home mother both have a total need satisfaction score of 15, Sheldon and Niemiec hypothesize that the mother will experience higher levels of well-being compared to the entrepreneur because she has balanced need satisfaction. Thus, balance in need satisfaction facilitates psychological health after the sum of need satisfaction scores is accounted for. It is important to stress here that if the entrepreneur and the stay at home mother had different reported total sums for overall need satisfaction, for example, a total score of 14 (5-6-3) for the entrepreneur and a total score of 3 (1-1-1) for the stay at home mother, the entrepreneur should have better outcomes than the stay at home mother even though the mother is reporting balance across the satisfaction of her needs. Balance adds to the prediction of well-being only when the total amount of need satisfaction is controlled for.

In their pioneering work, Sheldon and Niemiec (2006) tested this hypothesis in four separate studies that utilized a diverse set of methodologies (i.e., cross-sectional, prospective, daily diary, and multiple reporter) and measures. In each study, college students who reported balanced need satisfaction reported higher well-being than those with the same sum score but who report greater variability in need satisfaction. Although the effect sizes for the positive impact of balance were modest, the fact that balance added to the prediction of well-being after controlling for the amount of need satisfaction in all four methodologically unique studies suggests that balance may be an informative construct in SDT that warrants further investigation.

Following Sheldon and Niemiec (2006), Milyavskaya et al. (2009) argued that while balance across each need may facilitate psychological health, considering how central the role of environmental context is in SDT, it seems likely that balance of need satisfaction across separate contexts should add even more to the prediction of wellbeing variables. For example, the discrepancy that the entrepreneur is experiencing in satisfaction across the three needs seems very context driven; where he is excelling at work at the expense of his home life. Milyavskaya and colleagues argue that because need satisfaction is a function of environmental support, variability across contexts should occur more frequently than would variability across needs.

Thus, Milyavskaya et al. (2009) extended Sheldon and Niemiec's (2006) balance construct to the realm of contexts, hypothesizing that although two individuals may report the same level of overall need satisfaction, the 
individual who experiences equal satisfaction of their needs across contexts should experience higher well-being than the individual whose need fulfillment fluctuates across contexts. In support of this new balance construct, the authors cite the self-esteem and attachment literature which puts forth that over and above an individual's level of selfesteem or attachment security, the extent to which an individual shows consistency or balance across time and situations relates to well-being outcomes (Kernis 2005; La Guardia et al. 2000).

Milyavskaya et al. (2009) tested this new balance construct in two studies. In their first study the researchers administered the Children's Intrinsic Need Satisfaction Scale (CINSS; Koestner and Veronneau 2001) as a measure of satisfaction of the three needs and overall need satisfaction in the contexts of home, school, and with peers; a composite measure of well-being that included a nineitem scale of affect (Emmons 1992) and six statements measuring positive self-concept (Anderman 2002); and other outcome measures to 720 adolescents (ages 11-18 years, $M=14.5, S D=1.5$ ) across three Western countries. To test the hypotheses that: (a) need satisfaction at home, at school, and with peers would be positively related to well-being; and, (b) that a balance of need satisfaction across contexts would be positively related to well-being independent of the amount of satisfaction in each individual context, a multiple regression analysis was undertaken with the well-being composite measure as the dependent variable. As predicted, need satisfaction in each life domain was found to be significantly positively related to well-being at school, at home, and with friends such that higher reports of well being corresponded to higher satisfaction in each of the three contexts. Furthermore, results confirmed that the experience of a balance of need satisfaction across important life contexts predicted well-being over when the level of need satisfaction at home, at school, and with peers was controlled for.

To ensure that balance of overall need satisfaction across contexts added to the prediction of well-being above and beyond the previously related needs balance hypothesis, the regression analysis was repeated with balance across needs inserted in the model along with overall need satisfaction in the three contexts. Results of the analysis revealed that balance across needs was not a significant predictor of well-being in the sample while balance across contexts remained significant. The two balance variables were only moderately correlated, suggesting that balance across contexts is a unique construct with useful predictive ability.

In their second study, Milyavskaya et al. (2009) sought to replicate the above findings and extend them to an Eastern culture. Measures from the previous study were translated into Mandarin and administered to 581 Chinese adolescents (ages $12-18$ years, $M=15.78, S D=1.6$ ), from three schools in Yinchuan. Replicating the findings from the first study in this culturally distinct sample, need satisfaction in each context was found to be significantly positively related to well-being. Moreover, similar to their Western counterparts, Chinese adolescents who reported greater balance in the overall satisfaction of their needs across school, home, and peer contexts had significantly higher well-being than adolescents who experienced variability in satisfaction across these contexts.

This large-scale, cross-cultural program of research provides evidence that: (a) balance across contexts and balance of individual needs are distinct variables; (b) need satisfaction at home, at school, and with peers is associated with adolescents' well-being; and, (c) balance of overall need satisfaction across contexts has important ramifications on adolescents' well-being once the level of overall need satisfaction in the three contexts is controlled for.

\section{Summary and research objectives}

Taken together, the reviewed studies correspond to major gains in our understanding of the role of individual need satisfaction, overall need satisfaction across contexts, and balance of need satisfaction across contexts in the prediction of depressive symptoms and well-being outcomes in children and adolescents. Despite these advances, a concrete examination of SDT has yet to be undertaken in a developmentally comparative manner. Thus, the objective of the present research was to test the applicability of SDT across two developmental periods by examining the importance of individual needs (i.e., autonomy, competence, relatedness) and the role of balance across contexts (i.e., home, school, peers) in predicting depressive symptoms in children and in adolescents.

Specifically, the current study sought to address the present gap in the literature by examining the association between the satisfaction of intrinsic needs and depressive symptoms, the effect of balance across levels of individual need satisfaction on depressive symptoms, and the effect of balance of overall need satisfaction across contexts on depressive symptoms. Based on previous literature (Milyavskaya et al. 2009; Veronneau et al. 2005), SDT (Deci and Ryan 1985, 2008; Ryan and Deci 2000) and Cole's (1991) theory of depression, it was hypothesized that the satisfaction of some needs would be more salient in terms of their relationship with depressive symptoms for children than they would be for adolescents. It was further hypothesized that balance across levels of need satisfaction, as well as balance across contexts would relate to depressive symptoms in similar ways for both children and for adolescents. 


\section{Method}

\section{Participants}

Data was collected as part of two larger separate studies examining mood and self-esteem in two schooling systems (i.e., elementary and high school). The child sample consisted of 149 participants ( 98 male, 51 female) in grades four, five, and six in a Montreal, Quebec elementary school, with a mean age of 133 months $(S D=10.73)$, with 45 students from the fourth grade, 49 students from the fifth grade, and 54 students from the sixth grade. The adolescent sample consisted of 153 participants (58 male, 94 female, 1 missing) in grades 8, 9, 10, and 11, in a Montreal, Quebec high school, with a mean age of 180.11 months $(S D=13.3)$, with 45 students from the eighth grade, 59 students from the ninth grade, 36 students from the tenth grade, and 11 students from the eleventh grade. The school populations were comprised largely of working class to middle class families of various cultural backgrounds. The samples did not significantly differ on mother's highest level of education obtained or on household income.

\section{Measures}

Children's Intrinsic Need Satisfaction Scale (CINSS; Koestner and Veronneau 2001)

This 18-item questionnaire was adapted for use with child and adolescent populations from the Intrinsic Need Satisfaction Scale (Deci et al. 2001). The CINSS assesses children and adolescents' need satisfaction (i.e., autonomy, competence, and relatedness) across three contexts (i.e., at home, at school, and with peers). Participants respond to each question on a five-point Likert-scale, selecting whether each statement is "not at all true" (1), "slightly true" (2), "moderately true" (3), "mostly true" (4), or "completely true" (5). The CINSS consists of three 6-item subscales that represent the three intrinsic needs proposed by SDT. The autonomy subscale measures the extent to which the participant feels as if they act with volition (e.g., "I feel free to express myself at home"), while the competence subscale considers the extent to which the participant feels that they can master tasks and activities (e.g., "I feel I do things well at school"), finally, the relatedness scale taps into the extent that the participant feels they are socially connected with important others (e.g., "my teachers like me and care about me"). Furthermore, as the CINSS questions are worded in a context specific manner, three additional 6-item subscales based on the same items as the need subscales but scored differently, assess the extent to which intrinsic needs are fulfilled at home (e.g.,
"I feel I do things well at home"), at school (e.g., "I like to be with my teachers"), and with peers (e.g., "I feel I have a choice about which activities to do with my friends").

When administered in previous research, there was evidence to suggest acceptable reliability within subscales: at home $\alpha=.74$; at school $\alpha=.73$; and with peers $\alpha=.80$. (Milyavskaya et al. 2009) with higher reliability demonstrated when subscales are combined, as when examining overall need satisfaction (R. K. Koestner, personal communication, November 2, 2011). In the present child sample, reliability for each need subscale was as follows: autonomy $\alpha=.68$, competence $\alpha=.81$, and relatedness $\alpha=.75$. Reliability for the three need subscales combined was $\alpha=.85$. Reliability for each domain subscale was as follows: at home $\alpha=.76$, at school $\alpha=.82$, and with peers $\alpha=.78$. Reliability for the three domain subscales combined was $\alpha=.79$. In the present adolescent sample, reliability for each need subscale was as follows: autonomy $\alpha=.67$, competence $\alpha=.76$, relatedness $\alpha=.67$. Reliability for the three need subscales combined was $\alpha=.76$. Reliability for each domain subscale was as follows: at home $\alpha=.82$, at school $\alpha=.32$, and with peers $\alpha=.85$. Reliability for the three domain subscales combined was $\alpha=.70$.

\section{Children's depression inventory (CDI; Kovacs 1992)}

The CDI is a 27-item self-rated symptomatology scale devised to assess depressed affect. This widely used inventory measures standard symptoms of depression such as disturbance in mood, pleasure-seeking capacity, self-evaluations and interpersonal behaviours. Several items also address consequences of depression in specific contexts that are relevant to children, such as school, and thus suitable for use with 7-17-year-olds. For each item, children choose from one of three response options that best represent their feelings in the past 2 weeks. Each item is scored 0,1 , or, 2 with 0 representing an absence of the symptom, 1, a mild symptom, or 2, a definite symptom. Total scores range from 0 to 81 with higher scores being indicative of more emotional dysfunction. An example of the statements on the CDI is as follows: "I am sad once in a while", "I am sad many times", or "I am sad all the time." In various samples, the internal consistencies Cronbach's alpha for the CDI have been found to range from .71 to .89 , indicating good reliability. The test-retest reliability also appears to have an acceptable level of stability, ranging from .38 to .87 (Kovacs 1992). The CDI has good convergent validity with other measures of depression (i.e., Centre for Epidemiologic Studies Depression Scale for Children, $r=.58$; clinician's independent global ratings of depression, $r=.55$; Child Depression Scale, $r=.70$ ) and self-reported related measures of anxiety $(r=.58-.65)$ and 
demonstrates good divergent validity with measures of self-esteem ( $r=-.59$ to -.61$)$ (Doerfler et al. 1988; Kovacs 1981, 1992; Reynolds et al. 1985). Furthermore, the CDI has demonstrated good construct validity, especially in non-clinical populations (Sitarenios and Kovacs 1999).

\section{Procedure}

The procedure in both studies was identical. Parent consent, as well as student assent, was received prior to the first session. Each participant completed three one-on-one separate testing sessions with a trained graduate student. Each session was approximately $75 \mathrm{~min}$ in length and was conducted in a private room in the student's school. As a result of the scope of the larger project, not all measures in the current study were administered in the same session. That is, the CDI was administered in one session, the second session consisted of several measures of academic achievement that are not part of the current investigation, and the CINSS was administered in the final session. The ordering of sessions was counterbalanced prior to administration to avoid any contamination of possible testing order.

\section{Results}

This study utilizes data collected for two separate samples (e.g., child and adolescent) and thus, analyses were conducted independently for each sample. The procedure described by Sheldon and Niemiec (2006) that has been replicated in a host of other studies (Church et al. 2013; Dysvik et al. 2013; Mack et al. 2011; Milyavskaya et al. 2009; Perreault et al. 2007) was applied to the CINSS data to compute a needs balance variable and a context balance variable for both the elementary and high school samples.

\section{Computations of needs variables}

The needs balance variable represents the consistency with which participants rated their satisfaction across the three needs of autonomy, competence, and relatedness. This variable was computed by first calculating the absolute difference between a participant's score on each subscale (i.e., autonomy subscale score-competence subscale score; competence subscale score-relatedness subscale score; and relatedness subscale score-autonomy subscale score) and then summing together these difference scores for each set of subscales [i.e., (autonomy subscale scorecompetence subscale score) + (competence subscale score-relatedness subscale score) + (relatedness subscale score-autonomy subscale score)] to give a measure of the total divergence among the scores. Given the five-point scale, the total divergence among the scores could range from 0 (indicating no variability between the amount of satisfaction of autonomy, competence, and relatedness) to 9 (indicating the maximum possible variability between the satisfaction of autonomy, competence, and relatedness, for example, as yielded by scores of 1 on the autonomy subscale, 3 on the competence subscale, and 5 on the relatedness subscale). The final balance scores were transformed by subtracting each participant's total divergence score from the highest observed divergence score [e.g., 9 (highest observed score) -2 (participant divergence score)], creating the need balance variable in which higher scores corresponded to greater balance among the three needs.

In the same manner, a context balance variable was computed, describing the distributional balance of scores across the three context subscales. This variable represents the consistency with which participants rated their overall need satisfaction across the three contexts of school, home, and with peers. The context balance variable was computed by first calculating the absolute difference between a participant's score on each subscale (i.e., home subscale score - school subscale score; school subscale score peer subscale score; and peer subscale score - home subscale score) and then summing together these difference scores for each set of subscales [i.e., (home subscale score - school subscale score $)+($ school subscale score - peer subscale score $)+($ peer subscale score home subscale score)] to give a measure of the total divergence among the scores. Given the five-point scale, the total divergence among the scores could range from 0 (indicating no variability between the amount of need satisfaction at home, at school, and with peers) to 9 (indicating the maximum possible variability between need satisfaction at home, at school, and with peers, for example, as yielded by scores of 1 on the home subscale, 3 on the school subscale, and 5 on the peer subscale). The final balance scores were transformed by subtracting each participant's total divergence score from the highest observed divergence score [e.g., 9 (highest observed score) - 2 (participant divergence score)], creating the need balance variable in which higher scores corresponded to greater balance in need satisfaction across the three contexts.

Table 1 presents the means and standard deviations of the measures of satisfaction of the three needs, balance of satisfaction across the three needs, need satisfaction in each of the three contexts, balance of satisfaction across contexts, and the measure of depressive symptoms, as well as the intercorrelations of these measures in the child sample. Table 2 presents the same information in the adolescent sample. 
Table 1 Means, standard deviations, and correlations of study variables in child sample

\begin{tabular}{|c|c|c|c|c|c|c|c|c|c|}
\hline Variable & $M(S D)$ & 1 & 2 & 3 & 4 & 5 & 6 & 7 & 8 \\
\hline \multicolumn{10}{|l|}{ Needs } \\
\hline Autonomy & $4.01(.68)$ & - & & & & & & & \\
\hline Competence & $4.34(.60)$ & $.61 * *$ & - & & & & & & \\
\hline Relatedness & $4.52(.52)$ & $.62 * *$ & $.80 * *$ & - & & & & & \\
\hline Need Balance & $6.01(.88)$ & $.56 * *$ & -.11 & .02 & - & & & & \\
\hline \multicolumn{10}{|l|}{ Needs in context } \\
\hline Home & $4.39(.60)$ & $.75 * *$ & $.68 * *$ & $.70 * *$ & $.20 *$ & - & & & \\
\hline School & $4.11(.68)$ & $.76^{* *}$ & $.80 * *$ & $.79 * *$ & .16 & $.63 * *$ & - & & \\
\hline Peers & $4.40(.65)$ & $.60 * *$ & $.80 * *$ & $.75^{* *}$ & .07 & $.43^{* *}$ & $.60 * *$ & - & \\
\hline Context balance & $4.27(1.05)$ & $.31 * *$ & $.49 * *$ & $.44 * *$ & .05 & $.28 * *$ & $.51 * *$ & $.32 * *$ & - \\
\hline \multicolumn{10}{|c|}{ Depressive symptoms } \\
\hline Total CDI & $45.46(9.00)$ & $-.43 * *$ & $-.51 * *$ & $-.45^{* *}$ & -.04 & $-.50 * *$ & $-.48 * *$ & $-.38 * *$ & $-.41 * *$ \\
\hline
\end{tabular}

Means and standard deviations are presented for each subscale. CDI Total score is a mean $T$-score. Indicates significant correlation at $* p<.05$ level, $* * p<.01$ level

Table 2 Means, standard deviations, and correlations of study variables in adolescent sample

\begin{tabular}{|c|c|c|c|c|c|c|c|c|c|}
\hline Variable & $M(S D)$ & 1 & 2 & 3 & 4 & 5 & 6 & 7 & 8 \\
\hline \multicolumn{10}{|l|}{ Needs } \\
\hline Autonomy & $3.92(.64)$ & - & & & & & & & \\
\hline Competence & $4.01(.69)$ & $.48 * *$ & - & & & & & & \\
\hline Relatedness & $4.05(.55)$ & $.54 * *$ & $.56 * *$ & - & & & & & \\
\hline Need balance & $6.06(1.00)$ & $.24 * *$ & .06 & .06 & - & & & & \\
\hline \multicolumn{10}{|l|}{ Needs in context } \\
\hline Home & $4.05(.71)$ & $.71 * *$ & $.62 * *$ & $.70 * *$ & .06 & - & & & \\
\hline School & $3.70(.61)$ & $.64 * *$ & $.61 * *$ & $.76 * *$ & .06 & $.55 * *$ & - & & \\
\hline Peers & $4.26(.58)$ & $.63 * *$ & $.51 * *$ & $.55 * *$ & .00 & $.33 * *$ & $.45 * *$ & - & \\
\hline Context balance & $3.79(1.02)$ & $.33 * *$ & $.35 * *$ & $.46^{* *}$ & .05 & $.38 * *$ & $.66^{* *}$ & .04 & - \\
\hline \multicolumn{10}{|c|}{ Depressive symptoms } \\
\hline Total CDI & $47.55(9.14)$ & $-.46^{* *}$ & $-.42 * *$ & $-.45 * *$ & -.03 & $-.49 * *$ & $-.55 * *$ & $-.26 * *$ & $-.46^{* *}$ \\
\hline
\end{tabular}

Means and standard deviations are presented for each subscale. CDI Total score is a mean $T$-score. Indicates significant correlation at $* * p<.01$ level

\section{Children's need satisfaction}

To determine (a) the association between the satisfaction of intrinsic needs; (b) the effect of balance across levels of individual need satisfaction; and, (c) the effect of balance of overall need satisfaction across contexts on children's depressive symptoms, a regression analysis was run with depressive symptomatology as measured by the CDI as the dependent variable. Gender and grade were controlled for and entered in Step 1 of the model, satisfaction of autonomy, competence, and relatedness were entered in Step 2 , balance of the level of satisfaction of individual needs was entered in Step 3, and balance of overall need satisfaction across contexts was entered in Step 4. An initial exploration of the distribution of the depressive symptoms scores revealed approximately normal distributions, with skewness and kurtosis values lying between -1.00 and 1.00 .

For children, gender and grade were not found to be significant predictors of depressive symptoms. In line with the original hypothesis, only satisfaction of the need for competence was found to be significantly negatively related to depressive symptoms, $\beta=-.36(p=.003)$ in this sample. The second step of the regression model accounted for a significant change of explained variance $\Delta \mathrm{R}^{2}$ of .32 , $F(3,132)=23.11, p<.001$. As hypothesized, balance 
across levels of individual needs was not a significant predictor of depressive symptoms in the child sample. Needs balance across contexts was a significant predictor of depressive symptoms over and above gender, satisfaction of each individual need, and balance of level of individual need satisfaction, $\beta=-.18, p=.024 ; \Delta \mathrm{R}^{2}$ of .02 , $F(1,130)=5.24, p=.024$. Details of this analysis are presented in Table 3.

\section{Adolescents' need satisfaction}

To determine (a) the association between the satisfaction of intrinsic needs; (b) the effect of balance across levels of individual need satisfaction; and, (c) the effect of balance of overall need satisfaction across contexts on adolescents' depressive symptoms, a second regression analysis was run with depressive symptomatology as measured by the CDI as the dependent variable. As in the first regression, gender and grade were controlled for and entered in Step 1 of the model, satisfaction of autonomy, competence, and relatedness were entered in Step 2, balance of the level of satisfaction of individual needs was entered in Step 3, and balance of overall need satisfaction across contexts was entered in Step 4. An initial exploration of the distribution of the depressive symptoms scores revealed approximately normal distributions, with skewness and kurtosis values lying between -1.00 and 1.00 .

As expected, gender was found to be a significant predictor of depressive symptoms, $\beta=.24$ ( $p=.003$ ) for adolescents. Grade was not found to be a significant predictor of depressive symptoms in this sample. In partial support of the hypothesis, satisfaction of autonomy, $\beta=$

Table 3 Hierarchical multiple regression analyses predicting depressive symptoms from need satisfaction and balance in children

\begin{tabular}{lrrrrc}
\hline Predictor & $B$ & $S E B$ & $\Delta \mathrm{R}^{2}$ & $\beta$ & Full model $\beta$ \\
\hline Step 1 & & & .03 & & \\
Gender & 2.50 & 1.54 & & .13 & $.20^{* *}$ \\
Grade & -1.31 & .90 & & -.12 & -.11 \\
Step 2 & & & $.32^{* * *}$ & & \\
Autonomy & -2.31 & 1.19 & & -.17 & $-.33^{*}$ \\
Competence & -5.46 & 1.78 & & $-.36^{* *}$ & -.20 \\
Relatedness & -1.88 & 2.09 & & -.11 & -.07 \\
Step 3 & & & .00 & & \\
Need balance & .72 & 1.22 & & .07 & .14 \\
Step 4 & & & $.02 *$ & & \\
Context balance & -1.63 & .71 & & $-.18^{*}$ & $-.19 *$ \\
Total $R^{2}$ & & & & $.37^{*}$ & \\
$n$ & & & & 149 & \\
\hline
\end{tabular}

Indicates significant correlation at $* p<.05$, ** $p<.01$, and $* * * p<.001$ level $-.25(p=.003)$, and relatedness, $\beta=-.22(p=.014)$, were found to be significant predictors of depressive symptoms for adolescents, although competence was not. The second step of the regression model accounted for a significant change of explained variance $\Delta \mathrm{R}^{2}$ of $.27, F(3$, $137)=19.55, p<.001$. Consistent with the hypothesis, balance of level of individual need satisfaction was not a significant predictor of depressive symptoms in the adolescent sample. As predicted, need balance across contexts was a significant predictor of depressive symptoms over and above gender, each individual need, and balance of level of need satisfaction of individual needs, $\beta=-.24$, $p=.002 ; \Delta \mathrm{R}^{2}$ of $.04, F(1,135)=9.55, p=.002$. Details of this analysis are presented in Table 4.

\section{Discussion}

The present study was the first to examine the predictive role of intrinsic need satisfaction on depressive symptoms in a developmentally comparative way, finding that the importance of individual need satisfaction in predicting depressive symptoms appears to vary as a function of developmental period. In a sample of children, regression analysis revealed that the satisfaction of the need for competence was related to depressive symptoms while this relationship was not found for the needs of autonomy and relatedness. However, in an adolescent sample, regression analysis revealed that the satisfaction of competence did not predict depressive symptoms whereas satisfaction of the needs of autonomy and relatedness did have an effect. While findings from the regression analyses indicate that

Table 4 Hierarchical multiple regression analyses predicting depressive symptoms from need satisfaction and balance in adolescents

\begin{tabular}{|c|c|c|c|c|c|}
\hline Predictor & $B$ & $S E B$ & $\Delta \mathrm{R}^{2}$ & $\beta$ & Full model $\beta$ \\
\hline Step 1 & & & $.07 *$ & & \\
\hline Gender & 4.56 & 1.49 & & $.24^{*}$ & .21 \\
\hline Grade & .46 & .80 & & .05 & .02 \\
\hline Step 2 & & & $.23 * *$ & & \\
\hline Autonomy & -3.64 & 1.20 & & $-.25^{* *}$ & $-.26 * *$ \\
\hline Competence & -2.03 & 1.14 & & -.15 & -.13 \\
\hline Relatedness & -3.70 & 1.49 & & $-.22 *$ & -.12 \\
\hline Step 3 & & & .00 & & \\
\hline Need balance & .40 & .65 & & .04 & .05 \\
\hline Step 4 & & & $.05^{*}$ & & \\
\hline Context balance & -2.18 & .71 & & $-.24 *$ & $-.25 * *$ \\
\hline Total $R^{2}$ & & & & $.38 *$ & \\
\hline$n$ & & & & 153 & \\
\hline
\end{tabular}


some needs are more salient predictors than others in both samples, a careful analysis of the correlations between the satisfaction of each need with depressive symptoms in children and in adolescents and the full regression model standardized betas draws a warning for over interpreting the regression findings. That is, although only some needs were significant predictors of the dependent variable within the multiple steps of the regression analyses, the correlations between the three needs and depressive symptoms are extremely similar in magnitude. Therefore, although some needs may be particularly salient within a developmental period, it is likely that the satisfaction of all needs plays a role in the experience of depressive symptoms.

The central role that one's social life and identity formation take on in adolescence may account for the influence of the fulfillment of the needs of relatedness and autonomy to depressive symptoms (Berndt 1979; Erikson 1968). As children enter into adolescence they begin to spend more unsupervised time with their same age peers in and outside of the school setting (Barnes et al. 2007). Popularity and peer acceptance become of prime importance, predicting both adaptive and minor delinquent behaviours (Allen et al. 2005). At the same time, another salient developmental task for young adolescents is increased autonomous functioning (Ryan 1993; Ryan and LaGuardia 2000). Adolescents' move towards independence is seen as an organically occurring developmental process (Steinberg and Silverberg 1986). While this development of independence may occur without outside influence, findings suggest that parents' promotion of volitional functioning by being empathetic, providing choices, and minimizing control, is predictive of adolescents' psychosocial functioning as indexed by levels of depression, self-esteem, and social well-being (Soenens et al. 2007). Thus, empirical evidence suggests that the satisfaction of the need for relatedness through the newfound importance of the peer group and the satisfaction of the need for autonomy through natural developmental processes and aided by parental support may be particularly salient at this developmental period.

The finding that the satisfaction of competence was not a significant predictor of depressive symptoms in adolescence is somewhat surprising considering that previous findings have extended Cole's competency model to adolescent and young adult populations (Tram and Cole 2000; Uhrlass et al. 2009). However, despite the non-significant finding, satisfaction of competence was significantly negatively correlated with depressive symptoms, suggesting a relationship between these two variables in this sample. It seems likely that competency in some domains may overlap with the three intrinsic needs. For example, perhaps in adolescence, fulfilling the very salient need for relatedness may be viewed as social competence; at this age it may be more important to belong to a peer group of close others than to face optimal challenges within that group. While these possibilities have not yet been empirically examined, the current finding speaks to Cole's (1991) caveat of developmental overgeneralization and Ryan and Deci's (2000) notes on the relative salience of needs across development. As these results suggest, one cannot assume that because fulfillment of the need for competence is an important factor in the development of depressive symptoms in middle childhood, it will be of equal importance in adolescence and beyond.

Although some studies have found initial support for the inclusion of a needs balance variable in SDT research (Church et al. 2013; Perreault et al. 2007; Sheldon and Niemiec 2006), the present study found no such predictive ability of balance of individual need satisfaction for children and adolescents' depressive symptoms. Similarly, the need balance hypothesis was minimally predictive of wellbeing outcomes of collegiate athletes (Mack et al. 2011), did not predict intrinsic motivation over and above individual need satisfaction in workers (Dysvik et al. 2013), and held no predictive ability in Milyavskaya et al. (2009) cross-cultural samples of adolescents. This variability in results across studies that have tested a needs balance hypothesis may be due to the wide range of outcome measures being targeted as well as the broad age range of participants across studies. Furthermore, as the present study found that some needs were not predictive of the dependent variable in regression analyses, it makes sense that a balance of all three needs would also not be significant. That is, if satisfaction of competence is not as important a factor in determining an adolescent's psychological health outcomes compared with the role of other needs, it makes sense that experiencing a balance across the three needs would not be relevant. Instead, in the present sample, a salient predictor of depressive symptoms was that of balance of overall need satisfaction across contexts.

Lending support to Milyavskaya et al. (2009), balance of overall need satisfaction at home, at school, and with peers, predicted depressive symptoms after gender, grade, the level of individual need satisfaction, and the balance of level of individual need satisfaction was controlled for. Furthermore, this predictive ability held true for both children and adolescents. The finding that a balance of overall need satisfaction across contexts is equally predictive of depressive symptoms for children as it is for adolescents lends strength to SDT's initial axiom that some variables may stand the test of development. The results of the current study indicate that future child and adolescent research conducted under the SDT umbrella would benefit from examining the effects of balance across contexts when participants report the same sum score of overall 
need satisfaction. It is likely that, although two individuals report the same amount of overall need satisfaction, the individual who reports greater equilibrium of this satisfaction across contexts may report better psychological outcomes compared to the individual who reports a more uneven profile. Furthermore, to help guide this research, a reappraisal of the balance hypothesis should be considered to include predictions based on balance of overall need satisfaction across contexts and not simply balance among the satisfaction of the needs themselves.

Humans are complex and they function in a multitude of contexts. The present results suggest that it may be shortsighted to examine need satisfaction in one context alone, providing only a small snapshot of a much more intricate existence. When the total amount of need satisfaction between individuals is the same, perhaps a useful addition to better understand the picture of overall functioning may be the examination of the balance of satisfaction over multiple contexts. This idea of the experience of balance as important to well-being and unbalance as problematic to psychological health, is not a novel one.

From social mores that warn individuals not to place all of their eggs in one basket, to describing a person who is emotionally or mentally troubled as "unbalanced", to Aristotle's golden mean, individuals and societies have long recognized the value of living a balanced life. Considering the current and historical preponderance of these folkways, it is not surprising that the concepts of balance and internal consistency have been theorized upon and investigated in numerous domains in research (e.g., Chapman et al. 1994; Greenblatt 2002; Higgins 1987; Kernis 2005; Linville 1985; Stryker and Burke 2000; Swann 1990). The present study suggests that the self-determination literature could benefit from incorporating this long studied association.

\section{Limitations}

Future research would benefit from a longitudinal approach to dispel any cohort effects on observed differences between developmental periods. The CINSS is the only need satisfaction measure that offers domain specific subscales and that is specific to child and adolescent populations, making it an invaluable tool in the present study. However, the psychometric properties of a subscale alone are not as strong as when subscales are combined (R. K. Koestner, personal communication, November 2, 2011). The present study would have benefited from a more psychometrically sound measure. Future efforts are needed to construct tests of BPNT that are acceptable for child and adolescent populations. Furthermore, although past studies examining the role of need balance on maladaptive outcomes have applied psychological need fulfillment measures, the SDT literature has begun moving beyond this approach to include measures of need frustration to predict maladaptive outcomes (Vansteenkiste and Ryan 2013). For example, Bartholomew et al. (2011), used the Psychological Need Thwarting Scale (Bartholomew et al. 2011) to predict illbeing in athletes, after controlling for the role of need satisfaction. Recently, Sheldon and Hilpert (2012) constructed the Balanced Measure of Psychological Needs (BMPN) as a measure of satisfaction and dissatisfaction of autonomy, competence, and relatedness. The psychometric properties of the BMPN indicated that it would be a good alternative over other more widely used basic need satisfaction measures. Since the BMPN offers both a satisfaction and dissatisfaction scale, it could lend itself well to the present research, however, its validity within child and adolescent populations has yet to be determined. As the present study examines depressive symptoms, measuring need satisfaction without also including a measure of need frustration is a limitation.

The present study explored only depressive symptoms as an outcome measure. Future research should examine a wider array of dependent variables, for example, positive affect and vitality, to ensure a more complete picture of the effects of context balance on optimal functioning. A measure of competency across multiple domains such as the Self-Perception Profile for Children (Harter 1985) would be a useful addition to the present study and could provide insight as to the possible similarities and differences between the construct of competence used under Cole's competency based model of depression and the need for competence outlined in SDT.

When working with children and adolescent samples, often problems of arbitrary classification of developmental periods arise with researchers labeling age groups from middle-childhood, childhood, pre-adolescent, adolescent to late adolescent in very different ways (Cole et al. 1997, 2001; Furman and Buhrmester 1992; Hankin et al. 1998; Lewinsohn et al. 2003; Milyavskaya et al. 2009; Veronneau et al. 2005). The present study is no exception, defining the developmental periods of childhood and adolescence by comparing elementary and high school students. To address the ambiguous classification of developmental stages, future research should classify participants according to developmental theory.

\section{Clinical implications}

The present findings suggest that psychologists working with children and adolescents who are experiencing depressive symptoms should examine the extent to which overall need satisfaction is consistent at home, at school, and with peers. If need satisfaction is low in one context, 
psychologists could work with clients to determine how needs are being thwarted and to restore a balance.

Additionally, when working with children presenting with depressive symptoms, these results suggest that psychologists should pay special attention to their clients' feelings of competence. Providing clients with optimal challenges (i.e., challenges that are achievable yet difficult), gives them opportunities to increase feelings of competency. Optimal challenges should be targeted to the contexts in which competency is low, for example, if competency is low at school, remediation should be offered. When working with adolescents presenting with depressive symptoms, results suggest that psychologists should monitor their clients' feelings of autonomy and relatedness, providing an autonomy supportive environment for the client and helping them to feel connected with others in multiple contexts.

\section{Conclusion}

To conclude, in children and in adolescents, the satisfaction of the needs for autonomy, competence, and relatedness are related to reports of depressive symptoms. However, satisfaction of some needs may be more salient predictors of depressive symptoms as a function of developmental period. By incorporating balance into the conceptualization of need fulfillment, new research possibilities and a deepened understanding of the effects of intrinsic need satisfaction on psychological outcomes emerge. When working with child and adolescent clients, an understanding of which psychological needs are most salient to them as well as taking into account their need satisfaction across the multiple domains in their lives, may help to inform targeted interventions to help to relieve depressive symptoms.

\section{References}

Abela, J. R. Z., Aydin, C., \& Auerbach, R. P. (2007). Responses to depression in children: Reconceptualizing the relation among response styles. Journal of Abnormal Child Psychology, 35, 913-927. doi:10.1007/s10802-007-9143-2.

Adie, J. W., Duda, J. L., \& Ntoumanis, N. (2012). Perceived coachautonomy support, basic need satisfaction and the well- being and ill-being of elite youth soccer players: A longitudinal investigation. Psychology of Sport and Exercise, 13, 51-59. doi:10.1016/j.psychsport.2011.07.008.

Allen, J. P., Porter, M. R., McFarland, F. C., Marsh, P., \& McElhaney, K. B. (2005). The two faces of adolescents' success with peers: Adolescent popularity, social adaptation, and delinquent behaviour. Child Development, 76, 747-760. doi:10.1111/j.14678624.2005.00875.x.

Amarose, A. J., Anderson-Butcher, D., \& Cooper, J. (2009). Predicting changes in athletes' well-being from changes in need satisfaction over the course of a competitive season. Research Quarterly for Exercise and Sport, 80, 386-392. doi:10.1080/ 02701367.2009.10599575.

Anderman, E. M. (2002). School effects on psychological outcomes during adolescence. Journal of Educational Psychology, 94, 795-809. doi:10.1037//0022-0663.94.4.795.

Baard, P. P., Deci, E. L., \& Ryan, R. M. (2004). Intrinsic need satisfaction: A motivational basis of performance and well-being in two work settings. Journal of Applied Social Psychology 34, 2045-2068. Retrieved from http://www.selfdeterminationtheory. org/publications/browse-by-topic/137-paul-baards-publications

Barnes, G. M., Hoffman, J. H., Welte, J. W., Farrell, M. P., \& Dintcheff, B. A. (2007). Adolescents' time use: Effects on substance use, delinquency and sexual activity. Journal of Youth and Adolescence, 36, 697-710. doi:10.1007/s10964-006-9075-0.

Bartholomew, K. J., Ntoumanis, N., Ryan, R. M., Bosch, J. A., \& Thogersen-Ntoumanis, C. (2011a). Self-determination theory and diminished functioning: The role of interpersonal control and psychological need thwarting. Personality and Social Psychology Bulletin, 37, 1459-1473. doi:10.1177/014616721 1413125.

Bartholomew, K. J., Ntoumanis, N., Ryan, R. M., \& ThøgersenNtoumani, C. (2011). Psychological need thwarting in the sport context: Assessing the darker side of athletic experience. Journal of Sport \& Exercise Psychology, 33, 75-102. Retrieved from: http://eprints.bham.ac.uk/602/

Berndt, T. J. (1979). Developmental changes in conformity to peers and parents. Developmental Psychology, 15, 606-616. doi:10. 1037/0012-1649.15.6.608.

Birmaher, B., Ryan, N. D., Williamson, D. E., Brent, D. A., Kaufman, J., Dahl, R. E., Perel, J., \& Nelson, B. (1996). Childhood and adolescent depression: A review of the past 10 years. Part I. Journal of the American Academy of Child and Adolescent Psychiatry, 35, 1427-1439. Retrieved from http://www.ncbi. nlm.nih.gov/pubmed/8936909

Burt, K. B., Obradović, J., Long, J. D., \& Masten, A. S. (2008). The interplay of social competence and psychopathology over 20 years: Testing transactional and cascade models. Child Development, 79(2), 359-374. doi:10.1111/j.1467-8624.2007. 01130.x.

Burt, K. B., \& Roisman, G. I. (2010). Competence and psychopathology: Cascade effects in the NICHD study of early child care and youth development. Development and Psychopathology, 22(03), 557-567. doi:10.1017/s095457941000 0271.

Chapman, N. J., Ingersoll-Dayton, B., \& Neal, M. B. (1994). Balancing the multiple roles of work and caregiving for children, adults and elders. In G. W. Keita \& J. J. Hurrell Jr (Eds.), Job stress in a changing workforce: Investigating gender, diversity, and family issues. Washington, DC: American Psychological Association.

Church, A. T., Katigbak, M. S., Locke, K. D., Zhang, H., Shen, J., de Jesús Vargas-Flores, J.,.. \& Ching, C. M. (2013). Need satisfaction and well-being testing self-determination theory in eight cultures. Journal of Cross-Cultural Psychology, 44(4), 507-534. doi:10.1177/0022022112466590

Cicchetti, D. (1990). An historical perspective on the discipline of developmental psychopathology. In J. Rolf, A. Masten, D. Cicchetti, K. Nuechterlein, \& S. Weintraub (Eds.), Risk and protective factors in the development of psychopathology (pp. 2-28). New York: Cambridge University Press.

Cole, D. A. (1991). Preliminary support for a competency-based model of depression in children. Journal of Abnormal Psychology, 100, 181-190. doi:10.1037/0021-843X.100.2.181.

Cole, D. A., Jacquez, F. M., \& Maschman, T. L. (2001). Social origins of depressive cognitions: A longitudinal study of self-perceived 
competence in children. Cognitive Therapy and Research, 25, 377-395. doi:10.1023/A:1005582419077.

Cole, D. A., Martin, J. M., \& Powers, B. (1997). A competency-based model of child depression: A longitudinal study of peer, parent, teacher, and self-evaluations. Journal of Child Psychology and Psychiatry, 38, 505-514. doi:10.1111/j.1469-7610.1997. tb01537.x.

Deci, E. L., \& Ryan, R. M. (1985). The general causality orientations scale: Self-determination in personality. Journal of Research in Personality, 19, 109-134. doi:10.1016/0092-6566(85)90023-6.

Deci, E. L., \& Ryan, R. M. (2008). Self-determination theory: A macrotheory of human motivation, development, and health. Canadian Psychology, 49, 182-185. doi:10.1037/a0012801.

Deci, E. L., Ryan, R. M., Gagné, M., Leone, D. R., Usunov, J., \& Kornazheva, B. P. (2001). Need satisfaction, motivation, and well-being in the work organizations of a former eastern bloc country. Personality and Social Psychology Bulletin, 27, 930-942. doi:10.1177/0146167201278002.

Doerfler, L. A., Felner, R. D., Rowlison, R. T., Raley, P. A., \& Evans, E. (1988). Depression in children and adolescents: A comparative analysis of the utility and construct validity of two assessment measures. Journal of Consulting and Clinical Psychology, 56, 769-772. Retrieved from http://psycnet.apa. org/journals/ccp/56/5/769.html

Dysvik, A., Kuvaas, B., \& Gagné, M. (2013). An investigation of the unique, synergistic and balanced relationships between basic psychological needs and intrinsic motivation. Journal of Applied Social Psychology, 43, 1050-1064. doi:10.1111/jasp.12068.

Emmons, R. A. (1992). Abstract versus concrete goals: Personal striving level, physical illness, and psychological well-being. Journal of Personality and Social Psychlogy, 62, 292-300. doi:10.1037/0022-3514.62.2.292

Erikson, E. H. (1950). Childhood and society. New York: Norton.

Erikson, E. H. (1968). Identity, youth, and crisis. New York: Norton.

Finch, A. J., Saylor, C. F., \& Edwards, G. L. (1985). Children's depression inventory: Sex and grade norms for normal children. Journal of Consulting and Clinical Psychology, 53, 424-425. doi:10.1037/0022-006X.53.3.424.

Furman, W., \& Buhrmester, D. (1992). Age and sex differences in perceptions of networks of personal relationships. Child Development, 63, 103-115. doi:10.1111/j.1467-8624.1992.tb03599.x.

Garrison, C. Z., Jackson, K. L., Marsteller, F., McKeown, R. E., \& Addy, C. L. (1990). A longitudinal study of depressive symptomatology in young adolescents. Journal of the American Academy of Child and Adolescent Psychiatry, 28, 581-585. doi:10.1097/00004583-199007000-00011.

Gibb, B. E., \& Alloy, L. B. (2006). A prospective test of the hopelessness theory of depression in children. Journal of Clinical Child and Adolescent Psychology, 35, 264-274. doi:10.1207/s15374424jccp3502_10.

Greenblatt, E. (2002). Work/life balance: Wisdom or whining. Organizational Dynamics, 31, 177-193. doi:10.1016/S00902616(02)00100-6.

Hankin, B. L., Abramson, L. Y., Moffitt, T. E., Silva, P. A., McGee, R., \& Angell, K. E. (1998). Development of depression from preadolescence to young adulthood: Emerging gender differences in a 10-year longitudinal study. Journal of Abnormal Psychology, 107, 128-140. doi:10.1037/0021-843X.107.1.128.

Harter, S. (1985). Manual for the self-perception profile for children. Denver, CO: University of Denver.

Heath, N. L., \& Wiener, J. (1996). Depression and nonacademic selfperceptions in children with and without learning disabilities. Learning Disability Quarterly, 19, 34-44. Retrieved from http:// www.jstor.org/stable/1511051

Heppner, W. L., Kernis, M. H., Nezlek, J. B., Foster, J., Lakey, C. E., \& Goldman, B. M. (2008). Within-person relationships among daily self-esteem, need satisfaction, and authenticity. Psychological Science, 19, 1140-1145. doi:10.1111/j.1467-9280.2008. 02215.x.

Higgins, E. T. (1987). Self-discrepancy: A theory relating self and affect. Psychological Review, 94(3), 319-340. doi:10.1037/ 0033-295X.94.3.319.

Howell, R. T., Chenot, D., Hill, G., \& Howell, C. J. (2011). Momentary happiness: The role of psychological need satisfaction. Journal of Happiness Studies, 12(1), 1-15. doi:10.1007/ s10902-009-9166-1.

Ilardi, B. C., Leone, D., Kasser, T., \& Ryan, R. M. (1993). Employee and supervisor ratings of motivation: Main effects and discrepancies associated with job satisfaction and adjustment in a factory setting. Journal of Applied Social Psychology, 23, 1789-1805. doi:10.1111/j.1559-1816.1993.tb01066.x.

Kernis, M. H. (2005). Measuring self-esteem in context: The importance of stability of self-esteem in psychological functioning. Journal of Personality, 73, 1569-1605. doi:10.1111/j.14676494.2005.00359.x.

Kessler, R. C. (1997). The effects of stressful life events on depression. Annual Review of Psychology, 48, 191-214. doi:10.1146/annurev.psych.48.1.191.

Koestner, R. F., \& Veronneau, M. H. (2001). The Children's Intrinsic Needs Satisfaction Scale. Unpublished questionnaire. Montreal: McGill University.

Kovacs, M. (1981). Rating scales to assess depression in school-aged children. Acta Paedopsychiatra, 46, 305-315. Retrieved from http://psycnet.apa.org/index.cfm?fa=search.displayRecord\&uid= 1981-31663-001

Kovacs, M. (1992). Children's depression inventory manual. North Tonawanda, NY: Multi-Health Systems.

La Guardia, J. G., Ryan, R. M., Couchman, C. E., \& Deci, E. L. (2000). Within-person variation in security of attachment: A self-determination theory perspective on attachment, need fulfillment, and well-being. Journal of Personality and Social Psychology, 79, 367-384. doi:10.1037/0022-3514.79.3.367.

Lewinsohn, P. M., Pettit, J. W., Joiner, T. E, Jr, \& Seeley, J. R. (2003). The symptomatic expression of major depressive disorder in adolescents and young adults. Journal of Abnormal Psychology, 112, 244-252. doi:10.1037/0021-843X.112.2.244.

Linville, P. W. (1985). Self-complexity and affective extremity: Don't put all of your eggs in one cognitive basket. Social Cognition, 3, 94-120. doi:10.1521/soco.1985.3.1.94.

Mack, D. E., Wilson, P. M., Oster, K. G., Kowalski, K. C., Crocker, P. R. E., \& Sylvester, B. D. (2011). Well-being in volleyball players: Examining the contributions of independent and balanced psychological need satisfaction. Psychology of Sport and Exercise, 12, 533-539. doi:10.1016/j.psychsport.2011.05. 006.

Masten, A. S., Roisman, G. I., Long, J. D., Burt, K. B., Obradović, J., Riley, J. R.,... \& Tellegen, A. (2005). Developmental cascades: Linking academic achievement and externalizing and internalizing symptoms over 20 years. Developmental Psychology, 41(5), 733. doi:10.1196/annals.1376.003

Meyer, B., Enstrom, M. K., Harstveit, M., Bowles, D. P., \& Beevers, C. G. (2007). Happiness and despair on the catwalk: Need satisfaction, well-being, and personality adjustment among fashion models. The Journal of Positive Psychology, 2(1), 2-17. doi:10.1080/17439760601076635.

Milyavskaya, M., Gingras, I., Mageau, G. A., Koestner, R., Gagnon, H., Fang, J., \& Boiche, J. (2009). Balance across contexts: Importance of balanced need satisfaction across various life domains. Personality and Social Psychology Bulletin, 35, 1031-1045. doi:10.1177/0146167209337036.

Milyavskaya, M., \& Koestner, R. (2011). Psychological needs, motivation, and well-being: A test of self-determination theory 
across multiple domains. Personality and Individual Differences, 50, 387-391. doi:10.1016/j.paid.2010.10.029.

Patrick, H., Knee, C. R., Canevello, A., \& Lonsbary, C. (2007). The role of need fulfillment in relationship functioning and wellbeing: A self-determination theory perspective. Journal of Personality and Social Psychology, 92, 434-457. doi:10.1037/ 0022-3514.92.3.434.

Perreault, S., Gaudreau, P., Lapointe, M. C., \& Lacroix, C. (2007). Does it take three to tango? Psychological need satisfaction and athlete burnout. International Journal of Sport Psychology, 38, 437-450. Retrieved from: http://www.selfdeterminationtheory. org/

Prinstein, M. J., \& Aikins, J. W. (2004). Cognitive moderators of the longitudinal association between peer rejection and adolescent depressive symptoms. Journal of Abnormal Child Psychology, 32, 147-158. doi:10.1023/B:JACP.0000019767.55592.63.

Quested, E., Bosch, J. A., Burns, V. E., Cumming, J., Ntoumanis, N., \& Duda, J. L. (2011). Basic psychological need satisfaction, stress-related appraisals, and dancers' cortisol and anxiety responses. Journal of Sport \& Exercise Psychology, 33, 828-846. Retrieved from http://www.selfdeterminationtheory. org/component/sdt/?view=SearchPublications\&task=domain Search\&domain $=2$

Reis, H. T., Sheldon, K. M., Gable, S. L., Roscoe, J., \& Ryan, R. M. (2000). Daily well-being: The role of autonomy, competence, and relatedness. Personality and Social Psychology Bulletin, 26, 419-435. doi:10.1177/0146167200266002.

Reynolds, W. M., Anderson, G., \& Bartell, N. (1985). Measuring depression in children: A multimethod assessment investigation. Journal of Abnormal Child Psychology, 13, 513-526. Retrieved from http://link.springer.com/article/10.1007/BF00923138

Rushton, J. L., Forcier, M., \& Schectman, R. M. (2002). Epidemiology of depressive symptoms in the national longitudinal study of adolescent health. Journal of the American Academy of Child and Adolescent Psychiatry, 41, 199-205. doi:10.1097/00004583200202000-00014.

Rutter, M. (1986). The developmental psychopathology of depression: issues and perspectives. In M. Rutter, C. Izard, \& P. Read (Eds.), Depression in young people: Developmental and clinical perspectives (pp. 3-30). New York: Guilford Press.

Ryan, R. M. (1993). Agency and organization: Intrinsic motivation, autonomy, and the self in psychological development. In J. E. Jacobs (Ed.), Developmental perspectives on motivation: Current theory and research in motivation (pp. 1-56). Lincoln, NE: University of Nebraska Press.

Ryan, R. M., \& Deci, E. L. (2000). Self-determination theory and the facilitation of intrinsic motivation, social development, and wellbeing. American Psychologist, 55, 68-78. doi:10.1037/0003066X.55.1.68.

Ryan, R. M., \& LaGuardia, J. G. (2000). What is being optimized? Self-determination theory and basic psychological needs. In N. Abeles \& S. H. Qualls (Eds.), Psychology and the aging revolution: How we adapt to longer life (pp. 145-172). Washington, DC: American Psychological Association.

Scheidt P., Overpeck M. D., Wyatt W., \& Aszmann A. (2000). Adolescents' general health and wellbeing. In WHO. (Ed.), Health and health behaviour among young people (pp. 24-28). Health policy for children and adolescents issue 1. Retrieved from http://www.euro.who.int/document/e67880.pdf

Seroczynski, A. D., Cole, D. A., \& Maxwell, S. E. (1997). Cumulative and compensatory effects of competence and incompetence on depressive symptoms in children. Journal of Abnormal Psychology, 106, 586-597. doi:10.1037/0021-843X.106.4.586.
Sheldon, K. M., \& Hilpert, J. C. (2012). The balanced measure of psychological needs (BMPN) scale: An alternative domain general measure of need satisfaction. Motivation and Emotion, 36(4), 439-451. doi:10.1007/s11031-012-9279-4.

Sheldon, K. M., \& Niemiec, C. P. (2006). It's not just the amount that counts: Balanced need satisfaction also affects well-being. Journal of Personality and Social Psychology, 91, 331-341. doi:10.1037/0022-3514.91.2.331.

Sheldon, K. M., Ryan, R. M., \& Reis, H. T. (1996). What makes for a good day? Competence and autonomy in the day and in the person. Personality and Social Psychology Bulletin, 22, 1270-1279. doi:10.1177/01461672962212007.

Sitarenios, G., \& Kovacs, M. (1999). Use of the Children's Depression Inventory. In M. E. Maruish (Ed.), The use of psychological testing for treatment planning and outcomes assessment (2nd ed., pp. 267-298). Mahwah, NJ: Erlbaum.

Soenens, B., Vansteenkiste, M., Lens, W., Luyckx, K., Goossens, L., Beyers, W., \& Ryan, R. M. (2007). Conceptualizing parental autonomy support: Adolescent perceptions of promotion of independence versus promotion of volitional functioning. Developmental Psychology, 43, 633-646. doi:10.1037/0012-1649.43. 3.633 .

Steinberg, L., \& Silverberg, S. B. (1986). The vicissitudes of autonomy in early adolescence. Child Development, 57, 841-851. doi:10.2307/1130361.

Stryker, S., \& Burke, P. J. (2000). The past, present, and future of an identity theory. Social Psychology Quarterly, 63, 284-297. Retrieved from http://www.jstor.org/stable/2695840

Swann, W. B, Jr. (1990). To be adored or to be known: The interplay of self-enhancement and self-verification. In R. M. Sorrentino \& E. T. Higgins (Eds.), Handbook of motivation and cognition (Vol. 2, pp. 408-448). New York: Guilford Press.

Thøgersen-Ntoumani, C., Ntoumanis, N., \& Nikitaras, N. (2010). Unhealthy weight control behaviours in adolescent girls: A process model based on self-determination theory. Psychology and Health, 25, 535-550. doi:10.1080/08870440902783628.

Tram, J. M., \& Cole, D. A. (2000). Self-perceived competence and the relation between life events and depressive symptoms in adolescence: Mediator or moderator? Journal of Abnormal Psychology, 109, 753-760. doi:10.1037/0021-843X.109.4.753.

Uhrlass, D. J., Schofield, C. A., Coles, M. E., \& Gibb, B. E. (2009). Self-perceived competence and prospective changes in symptoms of depression and social anxiety. Journal of Behaviour Therapy and Experimental Psychology, 40, 329-337. doi:10. 1016/j.jbtep.2009.01.001.

van de Broeck, A., Vansteenkiste, M., Witte, H., Soenens, B., \& Lens, W. (2010). Capturing autonomy, competence, and relatedness at work: Construction and initial validation of the Work-Related Basic Need Satisfaction scale. Journal of Occupational and Organizational Psychology, 83, 981-1002. doi:10.1348/ 096317909X481382.

Vansteenkiste, M., \& Ryan, R. M. (2013). On psychological growth and vulnerability: Basic psychological need satisfaction and need frustration as a unifying principle. Journal of Psychotherapy Integration, 23, 263-280. doi:10.1037/a0032359.

Veronneau, M., Koestner, R. F., \& Abela, J. R. Z. (2005). Intrinsic need satisfaction and well-being in children and adolescents: An application of the self-determination theory. Journal of Social and Clinical Psychology, 24, 280-292. Retrieved from http:// search.proquest.com/docview/224839930?accountid=12339 